\title{
Real-World Contribution of Electrification and Replacement Scenarios to the Fleet Emissions in West Midland Boroughs, UK
}

\author{
Louisa K. Osei $(\mathbb{D}$, Omid Ghaffarpasand $(\mathbb{1}$ and Francis D. Pope *(1) \\ School of Geography, Earth, and Environmental Sciences, University of Birmingham, Birmingham B15 2TT, UK; \\ LKO808@student.bham.ac.uk (L.K.O.); o.ghaffarpasand@bham.ac.uk (O.G.) \\ * Correspondence: f.pope@bham.ac.uk
}

Citation: Osei, L.K.; Ghaffarpasand, O.; Pope, F.D. Real-World

Contribution of Electrification and Replacement Scenarios to the Fleet Emissions in West Midland Boroughs, UK. Atmosphere 2021, 12, 332. https://doi.org/10.3390/ atmos12030332

Academic Editor: Antonio Donateo

Received: 14 January 2021

Accepted: 11 February 2021

Published: 4 March 2021

Publisher's Note: MDPI stays neutral with regard to jurisdictional claims in published maps and institutional affiliations.

Copyright: (c) 2021 by the authors. Licensee MDPI, Basel, Switzerland. This article is an open access article distributed under the terms and conditions of the Creative Commons Attribution (CC BY) license (https:/ / creativecommons.org/licenses/by/ $4.0 /)$.

\begin{abstract}
This study reports the likely real-world effects of fleet replacement with electric vehicles (EVs) and higher efficiency EURO 6 vehicles on the exhaustive emissions of $\mathrm{NO}_{\mathrm{x}}, \mathrm{PM}$, and $\mathrm{CO}_{2}$ in the seven boroughs of the West Midlands (WM) region, UK. National fleet composition data, local EURO distributions, and traffic compositions were used to project vehicle fleet compositions for different roads in each borough. A large dataset of real-world emission factors including over 90,000 remote-sensing measurements, obtained from remote sensing campaigns in five UK cities, was used to parameterize the emission profiles of the studied scenarios. Results show that adoption of the fleet electrification approach would have the highest emission reduction potential on urban roads in WM boroughs. It would result in maximum reductions ranging from 35.0 to $37.9 \%, 44.3$ to $48.3 \%$, and 46.9 to $50.3 \%$ for $\mathrm{NO}_{\mathrm{x}}, \mathrm{PM}$, and $\mathrm{CO}_{2}$, respectively. In comparison, the EURO 6 replacement fleet scenario would lead to reductions ranging from 10.0 to $10.4 \%, 4.0$ to $4.2 \%$, and 6.0 to $6.4 \%$ for $\mathrm{NO}_{\mathrm{x}}, \mathrm{PM}$, and $\mathrm{CO}_{2}$, respectively. The studied mitigation scenarios have higher efficacies on motorways compared to rural and urban roads because of the differences in traffic fleet composition. The findings presented will help policymakers choose climate and air quality mitigation strategies.
\end{abstract}

Keywords: on-road emissions; real-world assessments; electrification; fleet renovating; mitigation strategies; West Midlands

\section{Introduction}

In recent decades, climate change has typically been regarded as the biggest global threat to civilisation [1-4]. Rising emissions of greenhouse gases (GHGs), such as carbon dioxide $\left(\mathrm{CO}_{2}\right)$, are recognised as principal factors in the acceleration of climate change [5]. Fossil fuel combustion, the backbone of the world's energy production, is the key driver of anthropogenic GHG emissions [6,7], and the transport sector accounts for over one-fifth of fossil fuel consumption and $26 \%$ of GHG emissions globally [8]. Transport is the only sector in which GHG emissions have risen since 1990 levels, while global GHGs emissions in other major sectors, such as the residential and industrial sectors, have been gradually declining over time [9]. Road vehicles have been considered one of the leading emission sources of particulate matter $(\mathrm{PM})$ and nitrogen oxides $\left(\mathrm{NO}_{\mathrm{x}}\right)$ [10]. A large proportion of literature explores the link between the concentration of these pollutants in urban environments and adverse health effects, see for example [11].

Despite the environmental drawbacks of the transport sector, it is a key foundation of the economy and crucial for the transfer of people, goods, and services [12]. In 2015, transportation contributed to around 5, 7, and 6\% of the gross domestic product (GDP) of Japan, the United States (US), and the European Union (EU), respectively [13]. The advancement of transportation in terms of both infrastructure and fleet composition plays a vital role in sustainable economic development [14]. Nevertheless, this progression has been accompanied by increased energy consumption and high levels of environmental pollution [5]. Hence, future developments in the sector must ensure sustainability in all transport dimensions [8]. 
For the aforementioned reasons, several strategies and action plans have been implemented to mitigate fleet emissions and drive a shift towards sustainable transport. Among the existing approaches, there is high interest in the viability of transport electrification as a climate mitigation strategy [9]. Using electric vehicles (EVs) in the urban fleet is highly advantageous as it means EVs emit no exhaust emissions (GHGs or air pollutants) which would help in the management of air pollution [15]. Although fleet electrification could significantly reduce the exhaustive emissions of $\mathrm{CO}_{2}$ and other air pollutants, it may increase emissions from other sources such as combustion-based electric power plants $[16,17]$. Recent reports have argued that adopting electric vehicles can have negative environmental impacts if full energy life cycle considerations were not sufficiently considered, like the source of energy, location of the power plant(s), and time of operation [18]. The results indicate that reduction in transport emissions (both exhaustive and non-exhaustive emissions) is critical for air quality attainment and must be integrated into climate change policies [16-18]. The carbon released from the use of petroleum-based fuels in the manufacturing process of EVs (embedded carbon) must also be taken into account, as the carbon intensity of EVs will depend on the energy mix of the source country $[9,18]$. Hence, in addition to the energy structure of a country or region, the contribution of electrification to the emission mitigation of different parts of the fleet should be addressed in detail. This provides a more realistic picture of the effectiveness of the scenario to a given transport system.

Manipulating the fleet by replacing vehicles with those of the latest emission standard, has also been recognised as another likely mitigation approach. This scenario is simpler than full electrification of the fleet, because the existing infrastructure does not need to change, and has attracted considerable attention after the implementation of low emission zones (LEZs) in European cities over the past decade. However, recent measurements using vehicle remote-sensing systems (VERSSs) have shown that reduction of vehicular emissions with the improvement of emission standards may not always be true in some real-world situations and for some vehicle classes, see for example $[19,20]$. Moreover, a wide body of research has demonstrated that the real-world reduction of vehicular emissions through the upgrading of emission standards is far from the projected reductions estimated from controlled laboratory conditions, see for example [19]. The issue of high-emitter vehicles, which are a small proportion of the fleet responsible for a significant amount of emissions, also increases concerns about the true effectiveness of the replacement strategy. Air quality in some European cities has not been significantly improved even after more than a decade since the implementation of LEZs, see for example [21,22]. Hence, the real-world efficacies of such mitigation scenarios are still open questions in research. The more stringent ultralow emissions zone (ULEZ) in London has made a big difference, the recent report from the office of the London mayor highlights a greater than $30 \%$ reduction in the on-road emission of $\mathrm{NO}_{x}$ after one-year of implementation of ULEZ [23].

In-depth research into the benefits and limitations of vehicle fleet manipulation, adoption of EVs, and other strategies helps to determine which approaches have the highest potential to allow reduction targets to be met. Vehicle fleet manipulation has already been parametrised and discussed in numerous studies. For example, Hao et al. investigates the impact of introducing five broad mitigation strategies to China's transport sector: constraining vehicle registration, reducing vehicle travel, enforcing vehicle consumption limits, vehicle downsizing, and introducing EVs [24]. The results show that the implementation of all five scenarios will lead to considerable fuel conservation and GHG mitigation at a national scale. In contrast, this localised study focuses specifically on vehicle fleet compositions and compares the effect EURO standard upgrading and EV adoption has on emissions. A study by Guo et al. considers four mitigation scenarios: emission standard updating, eliminating high emitting vehicles, regulating vehicle population, and promoting new energy vehicles (EVs and alternative fuels) [25]. The scenario integrating all four strategies led to a $59 \% \mathrm{NO}_{\mathrm{x}}$ emission reduction compared to business as usual. However, this study estimates vehicular emissions of $\mathrm{NO}_{\mathrm{x}}$ and PM. Gerstenberger et al. considered how 
changing passenger vehicle composition affects $\mathrm{NO}_{2}$ emissions [26]. Traffic volumes were used to calculate $\mathrm{NO}_{2}$ emissions within a road network. The results show that scenarios with higher proportions of EURO 6 replacement lead to lower $\mathrm{NO}_{2}$ emissions with less of the road network exceeding the NO2 threshold. However, the study concluded that EVs would be required to keep all road emissions of $\mathrm{NO}_{2}$ under the EU limit. Hill et al. argues that emission mitigation strategies focussed on EVs alone cannot help the UK reach its desired $\mathrm{CO}_{2}$ reduction by 2030 [9]. The study elucidates the lag between EV uptake and reduction benefits due to embedded carbon produced during manufacture. Implemented policies will take time to achieve the desired effect as the vehicle fleet proportion of EVs must first reach $60 \%$. Other mitigation strategies must also be considered to meet near and long-term goals. A major one being the decarbonisation of the UK's energy grid. A case study of Northern China by Wang et al. discusses the large emissions reduction potential of EVs. In Beijing, the progression to a cleaner energy mix means that the promotion of EVs could reduce the total local emissions of both $\mathrm{NO}_{x}$ and PM2.5 by more than 98\% [27]. Nanaki and Koroneos performs a study in Athens, evaluating the effect of alternative fuel penetration, showed that changes in fleet composition lead to significant reductions in air and $\mathrm{CO}_{2}$ emissions [8]. A scenario with $30 \%$ of the vehicle fleet composed of low emissions vehicles, of which $10 \%$ are EVs or plug-in hybrid electric vehicles (PHEVs), would lead to $57.2 \%, 49.7 \%, 21 \%$ reductions in $\mathrm{NO}_{\mathrm{x}}, \mathrm{PM}$, and $\mathrm{CO}_{2}$ emissions respectively. Ke et al. investigates three future electrification scenarios with zero, moderate, and full EV penetration [18]. The moderate scenario adopts EVs as $20 \%$ of the passenger and $80 \%$ of the commercial vehicle fleets. This study concludes that full EV penetration is required to gain air quality benefits. Ultimately, vehicle fleet manipulation has the potential to greatly reduce future emissions of air pollutants. Although fleet manipulation has been studied in many areas around the world, to the best of our knowledge, similar analyses have not been reported in the UK till this study.

Due to the importance of these types of studies, the results of the campaigns of a relatively new-to-market VERSS, i.e., EDAR [28], across five UK cities and the available fleet compositions were used to provide a thorough dissection of the efficacy of implementing electrification and replacement strategies on fleet emissions in the seven boroughs of the West Midlands, UK. This research may not only aid policymakers and government agencies but also various stakeholders in different sectors. The energy (production) sector; automotive industry; utility providers, and urban concept planners may also have an interest in the results of this study. The results of the present study could be used to inform local plans and legislations which will help the UK reach its emissions targets while also reducing mortality and morbidity associated with air pollution in the population [29].

\section{Air Pollution, Transport, and Energy Production in the UK}

Air pollution is a significant national issue, as only six UK counties were able to meet the annual WHO exposure limit for $\mathrm{NO}_{2}$ in 2015 [30,31]. Air pollution is also the cause of approximately 40,000 premature deaths in the UK every year, with links to both physical health and mental health [32]. The transport sector is one of the major contributors to UK air pollution. While transport in the UK contributed to around 19,736 Million GBP per quarter to the GDP pre-pandemic [33], the economic burden of outdoor air pollution and its associated morbidity and mortality is in the region of $£ 20$ billion annually [34]. Further financial losses can be attributed to high levels of $\mathrm{NO}_{\mathbf{x}}$ exacerbating eutrophication and affecting crop production [35]. The Climate Change Act, introduced to the UK in 2008, aims to reduce the UK's GHG emissions to 80\% of the 1990 levels by 2050 [29]. The UK government has introduced localised low and ultra-low emission zones (LEZ and ULEZ) in cities such as London in an attempt to limit the negative health effects of air pollution [36]. This aims to help the city to stay within WHO air quality guidelines [36]. The schemes target vehicles with the highest emission contributions by imposing restrictions on emissions. Similar strategies are to be introduced in other UK cities, such as Birmingham, in the near future [37]. Nevertheless, early identification and implementation of mitigation 
strategies which tackle these pollutants are crucial to supporting the population and the economy. The strategies implemented will work towards reducing future emissions and help to reach national and global emission targets [29].

As was mentioned earlier, the energy structure of a region plays a vital role in the true effectiveness of electrification strategies. Replacement of the fleet with EVs might have environmental drawbacks in areas with significant combustion-based energy sources. According to the recent energy profile of the UK, electrification strategies could be considered as promising solutions for mitigating the exhaustive emissions and also climate change [38]. The recent report from the Department for Business, Energy, and Industrial Strategy (BEIS) highlights that renewable energies account for over $47 \%$ of UK energy generation in the first quarter of 2020 [38]. Meanwhile, the contribution of renewable energy farms to the UK energy sector has been gently increased for the last years [38].

\section{Study Area}

The West Midlands (WM) county covers seven metropolitan boroughs: Birmingham, Coventry, Wolverhampton, Dudley, Sandwell, Solihull, and Walsall. WM has 27 different constituencies which are represented in Figure 1. These areas are governed by the West Midlands Combined Authority (WMCA). The WM metropolitan area is predominantly urban with some rural areas. Birmingham is the regional capital and largest city economy outside of London. It is the centre for retail and acts as a hub for employment, leisure, culture, and business. Birmingham, like the WM in general, has good physical connectivity due to being situated at the heart of the UK's railway and motorway networks. The Black Country consists of the four boroughs of Sandwell, Wolverhampton, Walsall, and Dudley, which collectively contribute to $£ 21.2$ billion of the WMCA's Gross Value Added (GVA) [39]. A summary of the socioeconomic characteristics of the West Midlands is reported in Table 1. Car use in the WM accounts for $63 \%$ of all journeys, which influences local air quality [40]. The WMCA has set a target of reducing the annual number of 'poor' air quality days from 37 days (current) to 1 day, by 2030 [40].

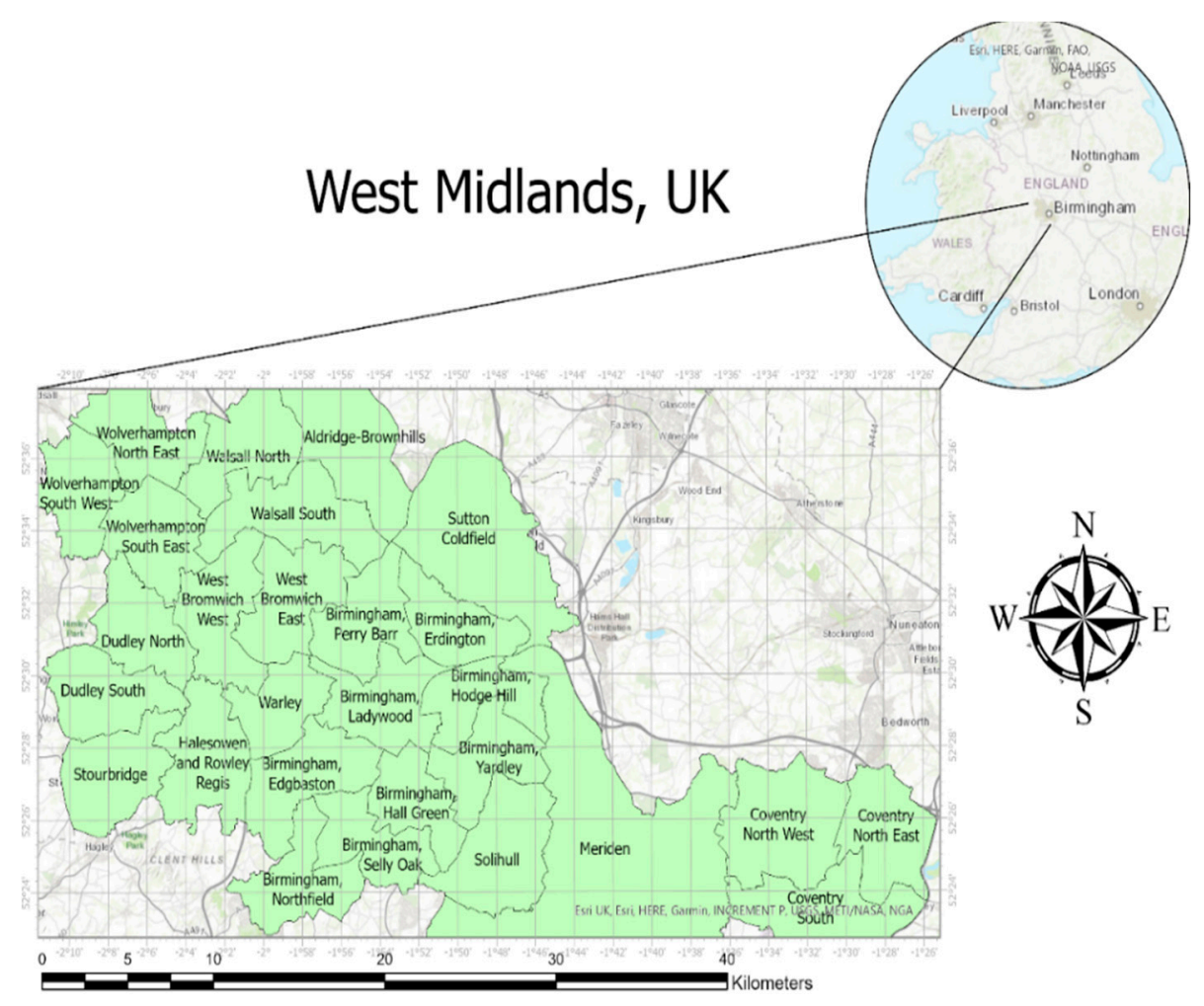

Figure 1. Map of the West Midlands, UK. The constituent boroughs are shaded in green. 
Table 1. Summary of WM socioeconomic status.

\begin{tabular}{cc}
\hline Land Area & $902 \mathrm{~km}^{2}$ \\
\hline Population & $2,607,000[41]$ \\
\hline GDP annual index & 101.3 million [42] \\
\hline Employment rate ${ }^{*}$ & $72.4 \%[40]$ \\
\hline 2019 pre-pandemic employment rate.
\end{tabular}

\section{Materials and Methods}

\subsection{Projection of Fleet Composition}

The study area is the constituent boroughs of West Midlands, UK. Traffic compositions in the West Midlands have been monitored by Transport for West Midlands (TfWM) for multiple years. This study used the TfWM dataset to extract the details of traffic composition within WM boroughs for the 2017 to 2019 period. The average traffic compositions of the studied areas are illustrated in Figure 2. Light-Goods vehicles (LGVs) are the dominant vehicle type in the WM on-road fleet. LGVs are usually accounted for passenger cars or taxis. Each kind of vehicle was then reclassified by road type, i.e., urban, rural, and motorway, and fuel type, i.e., petrol and diesel, using the available fleet composition data from the National Atmospheric Emission Inventory for outside London [43]. The average distributions of the different vehicle types for the 2017 to 2019 period are reported in Table 2.

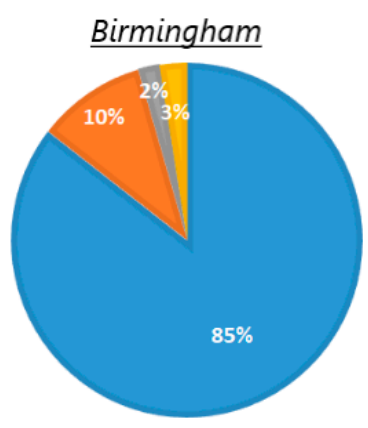

Dudley

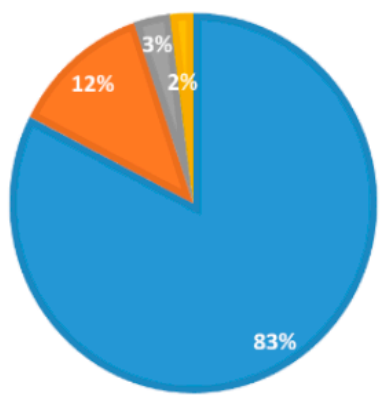

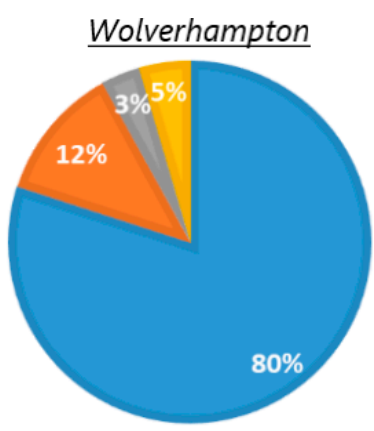

Walsall

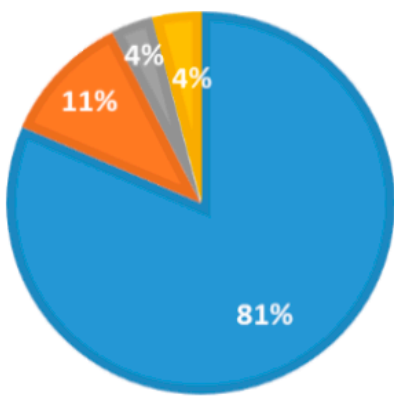

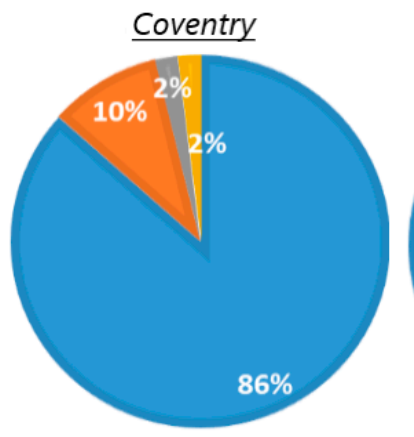

Solihull

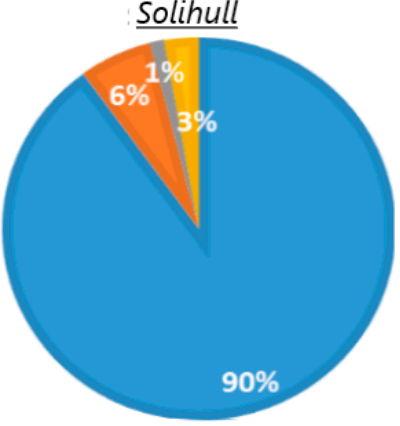

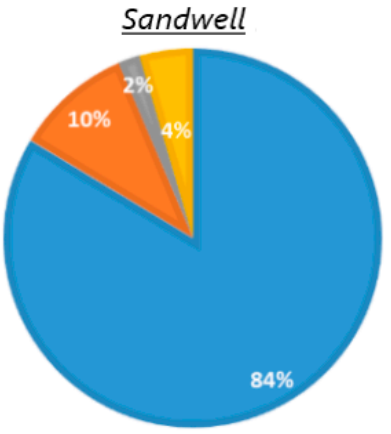

Cars

LGVs

HGVs

Buses

Figure 2. Traffic composition in the seven WM boroughs. These data were extracted from the Transport for West Midlands (TfWM).

The vehicles were subset according to their fuel type, class, and type of road transport by the following equation:

$$
C_{b, c, f, r}=\frac{C_{b, c} \times N F C o_{c, f, r}}{\sum_{c, f, r} \operatorname{NFCo}_{c, f, r}}
$$

where $C_{b, c, f, r}(\%)$ is the contribution of vehicle class $c$, type of fuel $f$, and road type $r$ to the fleet composition of borough $b, C_{b, c}(\%)$, and $N F C o_{c, f, r}(\%)$ are the contribution of the vehicle class $c$ to the traffic composition of borough $b$ and national fleet composition outside London for vehicle class $c$, type of fuel $f$ and road type $r$ (reported in Figure 2 and Table 1 ), 
respectively. The borough fleet composition for every vehicle class, road type, and type of fuel was then reclassified according to their EURO standard emission. The contribution of vehicle class $c$ with fuel type of $f$ and emission standard of $E$ (EURO E) in the road type of $r$ of the borough $b$ is determined by the factors of $E C_{b, c, f, r, E}(\%)$ which is given as:

$$
E C_{b, c, f, r, E}=\frac{C_{b, c, f, r} \times E U_{c, f, E}}{\sum_{c, f, E} E U_{c, f, E}}
$$

where $E U_{c, f, E}(\%)$ is the contribution of vehicles with EURO standard of $E$ in the studied fleet subset. The EURO distribution of every vehicle subset is determined by the automatic number plate recognition (ANPR) cameras [38]. ANPR cameras register the number plates of the passing vehicles and technical information of the collected samples such as the model, engine volume, EURO standard, and type of the fuel. This information is then extracted through the off-line matching against the existing vehicle archives in the UK such as the Driver Vehicle Licensing Authority (DVLA), the Society of Motor Manufacturers Traders (SMMT), and Motor Vehicle Registration Information System (MVRIS). We also use the results of five EDAR campaigns (please see the next section), which contain the data of over 90,000 number plates, to improve the estimated EURO profile within the WM roads networks. The wide campaigns of the ANPR cameras within the WM provide a detailed picture of EURO distributions within the studied areas [38]. The EURO standard profile of the studied fleet is reported in Table 3.

Table 2. Fleet distribution according to the fuel type. These data were extracted from the National Atmospheric Emission Inventory [43]. MC and PSV are corresponded with motorcycles and public service vehicle, respecively.

\begin{tabular}{|c|c|c|c|c|c|c|c|c|c|c|c|}
\hline Road Type & Year & $\begin{array}{c}\text { Electric } \\
\text { Car } \\
(\%)\end{array}$ & $\begin{array}{l}\text { Petrol } \\
\text { Car } \\
(\%)\end{array}$ & $\begin{array}{l}\text { Diesel } \\
\text { Car } \\
(\%)\end{array}$ & $\begin{array}{c}\text { Electric } \\
\text { LGV } \\
(\%)\end{array}$ & $\begin{array}{c}\text { Petrol } \\
\text { LGV } \\
(\%)\end{array}$ & $\begin{array}{c}\text { Diesel } \\
\text { LGV } \\
(\%)\end{array}$ & $\begin{array}{c}\text { Rigid } \\
(\%)\end{array}$ & $\begin{array}{c}\text { Artic } \\
(\%)\end{array}$ & $\begin{array}{l}\text { PSV } \\
(\%)\end{array}$ & $\begin{array}{l}\text { MC } \\
(\%)\end{array}$ \\
\hline \multirow{4}{*}{ Urban } & 2017 & 0.1 & 45.1 & 36.7 & 0.0 & 0.5 & 13.9 & 1.1 & 0.3 & 1.1 & 1.1 \\
\hline & 2018 & 0.2 & 44.3 & 37.7 & 0.0 & 0.4 & 13.8 & 1.1 & 0.3 & 1.1 & 1.0 \\
\hline & 2019 & 0.2 & 43.8 & 38.4 & 0.0 & 0.4 & 13.7 & 1.1 & 0.3 & 1.1 & 1.2 \\
\hline & Average & 0.2 & 44.4 & 37.6 & 0.0 & 0.4 & 13.8 & 1.1 & 0.3 & 1.1 & 1.1 \\
\hline \multirow{4}{*}{ Rural } & 2017 & 0.0 & 37.7 & 40.6 & 0.0 & 0.5 & 15.0 & 2.6 & 2.4 & 0.5 & 0.9 \\
\hline & 2018 & 0.0 & 36.7 & 41.7 & 0.0 & 0.4 & 15.0 & 2.5 & 2.4 & 0.5 & 0.9 \\
\hline & 2019 & 0.0 & 36.1 & 42.3 & 0.0 & 0.4 & 15.0 & 2.5 & 2.4 & 0.5 & 0.8 \\
\hline & Average & 0.0 & 36.8 & 41.5 & 0.0 & 0.4 & 15.0 & 2.5 & 2.4 & 0.5 & 0.9 \\
\hline \multirow{4}{*}{ Motorway } & 2017 & 0.0 & 28.1 & 45.7 & 0.0 & 0.5 & 13.3 & 3.7 & 8.2 & 0.3 & 0.4 \\
\hline & 2018 & 0.0 & 27.1 & 46.8 & 0.0 & 0.4 & 13.1 & 3.7 & 8.2 & 0.3 & 0.4 \\
\hline & 2019 & 0.0 & 26.5 & 47.5 & 0.0 & 0.4 & 12.9 & 3.7 & 8.3 & 0.3 & 0.4 \\
\hline & Average & 0.0 & 27.2 & 46.7 & 0.0 & 0.4 & 13.1 & 3.7 & 8.2 & 0.3 & 0.4 \\
\hline
\end{tabular}

Table 3. The distribution (\%) of EURO standard within the different vehicle types for 2016.

\begin{tabular}{ccccc}
\hline Vehicle Class $\backslash$ Euro Standard & $\mathbf{3}$ & $\mathbf{4}$ & $\mathbf{5}$ & $\mathbf{6}$ \\
\hline Petrol Cars & 4 & 23 & 34 & 39 \\
\hline Diesel Cars & 2 & 13 & 32 & 53 \\
\hline LGVs & 3 & 14 & 25 & 58 \\
\hline HGVs & 4.5 & 4 & 18.5 & 72 \\
\hline Buses & 15 & 11 & 16 & 58 \\
\hline
\end{tabular}




\subsection{Estimation of Fleet Emissions}

This study uses a large dataset including over 90,000 emission factors which were measured in real-world conditions during the field campaigns of emission detecting and reporting system (EDAR). EDAR was deployed in five UK urban environments from 20162017, please see [44] for more information. It is a remote-sensing-based system deployed above the roads to measure the real-world emission factors of moving vehicles at a single point in time. EDAR provides an image of the exhaust plume at the tailpipe of passing vehicles. A schematic diagram of EDAR deployment is illustrated in Figure 3. The applied remote-sensing technologies in EDAR provide comprehensive data on the exhaustive emissions of passing vehicles in urban environments [28]. In the present study, it has been assumed that all the driving conditions such as driving behaviour, weather conditions, and accumulated mileage are the same for all vehicle subsets. In other words, every vehicle subset contributes to the total fleet emission according to its specific emission factors under real-world conditions. Hence, the contribution of each fleet subset with vehicle class of $c$, type of fuel $f$, in the road type of $r$, EURO type $E$ to the emission of pollutant $p$ of borough $b$ is defined by the factor of $C F E_{b, c, f, r, E, p}(\%)$, which is given as:

$$
C F E_{b, c, f, r, E, p}=\frac{E C_{c, f, r, E} \times E F_{c, f, E, p}}{\sum_{c, f, E, p} E F_{c, f, E, p}}
$$

where $E F_{c, f, E, p}(\mathrm{~g} / \mathrm{km})$ is the exhaustive emission factor for vehicle class of $c$, type of fuel $f$, and EURO standard of $E$, and pollutant $p$. We consider three air pollutants here: $\mathrm{CO}_{2}, \mathrm{NO}_{\mathrm{x}}$, and PM. The emission factors were reported in detail in the study of [44]. The variables, parameters, and their possible correspondences are reported in Table 4 to help the readers understand the notation used.

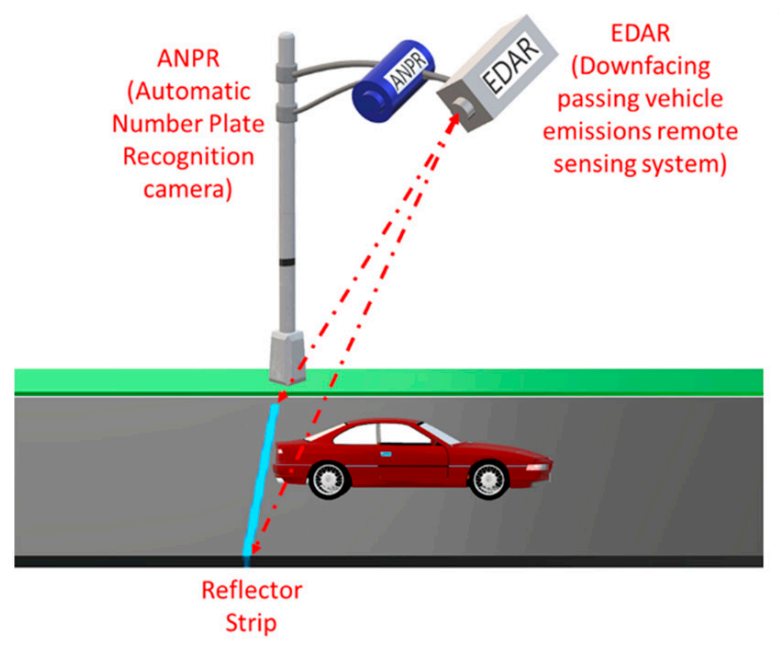

(a)

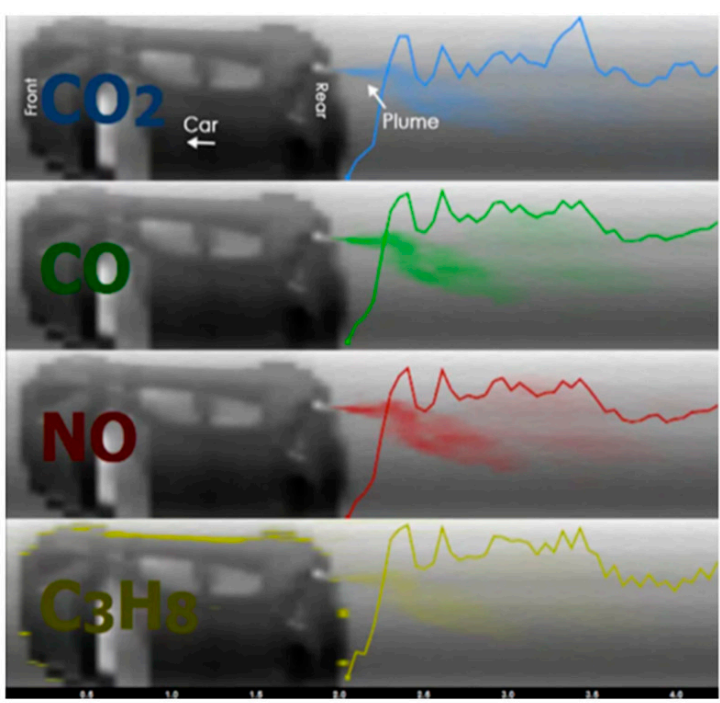

(b)

Figure 3. A schematic diagram of how EDAR is deployed on roads. (a) The alignment of the EDAR device to the road, (b) the information received by the EDAR device. 
Table 4. The list of introduced parameters and subscripts.

\begin{tabular}{|c|c|c|}
\hline \multicolumn{3}{|c|}{ Main Parameters } \\
\hline Parameter & \multicolumn{2}{|c|}{ Meaning } \\
\hline $\mathrm{C}$ & \multicolumn{2}{|c|}{ contribution to the fleet } \\
\hline NFCo & \multicolumn{2}{|c|}{ national fleet composition outside London } \\
\hline EC & \multicolumn{2}{|c|}{ EURO composition of the studied fleet subset } \\
\hline CFE & \multicolumn{2}{|c|}{ contribution to the emission of the studied fleet subset } \\
\hline EU & \multicolumn{2}{|c|}{ local EURO distribution } \\
\hline $\mathrm{EF}$ & \multicolumn{2}{|c|}{ real-world exhaustive emission factor } \\
\hline \multicolumn{3}{|c|}{ Subscripts } \\
\hline Index & Meaning & Likely Values \\
\hline \multirow[t]{3}{*}{$\mathrm{b}$} & \multirow[t]{3}{*}{ borough } & $\begin{array}{c}\text { Seven boroughs of West } \\
\text { Midlands }\end{array}$ \\
\hline & & Petrol Cars \\
\hline & & Diesel Cars \\
\hline \multirow[t]{3}{*}{ c } & \multirow[t]{3}{*}{ vehicle class } & LGVs \\
\hline & & HGVs \\
\hline & & Buses \\
\hline $\mathrm{f}$ & type of fuel & Diesel and Petrol \\
\hline $\mathrm{r}$ & road type & Motorway, Urban and Rural \\
\hline $\mathrm{E}$ & EURO standard & $3,4,5$, and 6 \\
\hline $\mathrm{p}$ & pollutant & $\mathrm{CO}_{2}, \mathrm{PM}$, and $\mathrm{NO}_{\mathrm{x}}$ \\
\hline
\end{tabular}

\section{Definition of Emission Reduction Scenarios}

We consider one baseline and two mitigation scenarios designed to include the most likely action plans to address the current and future issue of the on-road emissions in the boroughs of the West Midlands. The baseline scenario is business-as-usual (BAU), which represents the current status of the fleet within the studied areas. All considered scenarios are assessed against $100 \%$ total fleet emission of the BAU status. The following sections detail the defined scenarios for the present study. Both mitigation scenarios assume like for like changes in the fleet, i.e., the total number of vehicle types in each scenario remain the same, just the emission outputs of the vehicle type change. The mitigation scenarios represent idealised cases that are used to estimate best-case scenarios.

\subsection{Fleet Electrification}

Full fleet electrification is the first mitigation scenario. Replacing the fleet subsets with electric vehicles will reduce the exhaustive emissions. It should be noted that there are current challenges with the non-exhaustive emission of EVs, see, for example, [45,46]. As the exhaustive emissions of the vehicle subset will be removed through replacement with the corresponding electric vehicles, the contribution of the vehicle subset to the fleet population can be introduced as the efficacy of electrification for each vehicle subset. The contribution of each vehicle subset to the total fleet emission was estimated using Equation (3). This is defined as the factor of fleet electrification, otherwise referred to as $F E F$, hereafter.

\subsection{Fleet Replacement}

The fleet replacement was considered as the other mitigation scenario for this study. In this, it was assumed that all vehicle subsets are replaced with vehicles of the highest emission standards at the time of this study, i.e., EURO 6. To assess the effect of fleet replacement on contributions in different WM boroughs, the applied emission factors in Equation (3) were replaced with the corresponding EURO 6 factors, and then the relative difference between the former and latter values was considered as the efficacy of fleet replacement of the targeted vehicle subset. The factor of fleet replacement is introduced 
here as $F R V$ to discuss the efficacy of this scenario in different vehicle subsets in different WM boroughs.

\section{Results and Discussion}

The following sections will present the emission outcomes of fleet manipulation on urban roads of the WM through electrification and upgrading to EURO 6, respectively.

\subsection{Fleet Electrification Scenario, FEF Factor}

The results of fleet electrification on urban road emissions are shown in Figure 4. Since the business as usual situation contains a vehicle fleet which has a negligible electric vehicle component, the electrification of the fleet leads to a near $100 \%$ reduction in exhaust emissions compared to the current fleet. The general trend for the FEF scenario across the studied areas and pollutants is that electrification of all EURO 6 vehicle types would have the greatest emission reduction potential because of the dominant contribution of EURO 6 vehicles to the total fleet, even though the emission standards for EURO 6 are more stringent than lower EURO classes. In Figure $4 \mathrm{a}$ the $\mathrm{NO}_{\mathrm{x}}$ emissions reduction potential is highest for EURO 5 and EURO 6 cars where FEF ranges from $34.3-36.1 \%$ and $35.0-37.9 \%$, respectively. In terms of vehicle types, electrification of diesel cars in these EURO standards would have the highest reductions. The FEF for EURO 5 diesel cars ranges from $12 \%$ to $17.4 \%$ and from $12.3 \%$ to $17.8 \%$ for EURO 6 diesel cars across the seven boroughs. Electrification of buses has the potential to reduce a significant proportion of $\mathrm{NO}_{x}$ emissions, especially for EURO 3 buses in Sandwell, Wolverhampton, and Walsall, where reductions are $10.4 \%, 9.6 \%$, and $8.8 \%$, respectively. The electrification of EURO 6 HGVs would reduce the $\mathrm{NO}_{\mathrm{x}}$ emissions the most in Dudley $(8.5 \%)$, Walsall $(8.2 \%)$, and Wolverhampton $(7.9 \%)$, compared to the other boroughs.

In Figure $4 b$, the electrification of all EURO 6 vehicle types has the highest $\mathrm{CO}_{2} \mathrm{FEF}$ ranging from $46.9 \%$ to $50.3 \%$ across the seven boroughs. The EV replacement of EURO 6 petrol and diesel cars would have the highest reduction potential. The electrification of EURO 6 petrol cars yields $\mathrm{CO}_{2}$ emissions reductions ranging from $11.6 \%$ to $15.2 \%$ on urban roads. Again, Dudley, Walsall, and Wolverhampton have the highest FEF for HGVs with $10.2 \%, 10.3 \%$, and $10.1 \%$ for $\mathrm{CO}_{2}$, respectively. EURO 6 buses in Sandwell, Walsall, and Wolverhampton have the highest FEF compared to the other boroughs. The electrification of LGVs would result in $<10 \%$ reductions across the studied areas. Figure $4 \mathrm{c}$ shows that the highest PM reductions are from the electrification of all EURO 6 vehicle types. These reductions range from $44.3 \%$ to $48.3 \%$ across all WM boroughs. Dudley, Walsall, and Wolverhampton have the highest electrification efficacy for EURO 6 HGVs with $12.9 \%, 12.8 \%$, and $12.5 \%$ reductions in PM, respectively. Again, FEF is high for petrol and diesel vehicles.

Considering the carbon emission contribution from the production of new EVs, the adoption of EVs alone is not the solution to $\mathrm{CO}_{2}$ emission reduction. In the near term, the benefits of EV penetration into fleets will be limited by the presence of less efficient vehicles. However, over a longer period, EV adoption coupled with the decarbonisation of the power grid would be effective in the decarbonisation of transport and mitigation of carbon emissions [9]. In contrast, addressing the high $\mathrm{NO}_{\mathrm{x}}$ and $\mathrm{PM}$ emissions with fleet manipulation would have an immediate effect on local emissions and air quality. 

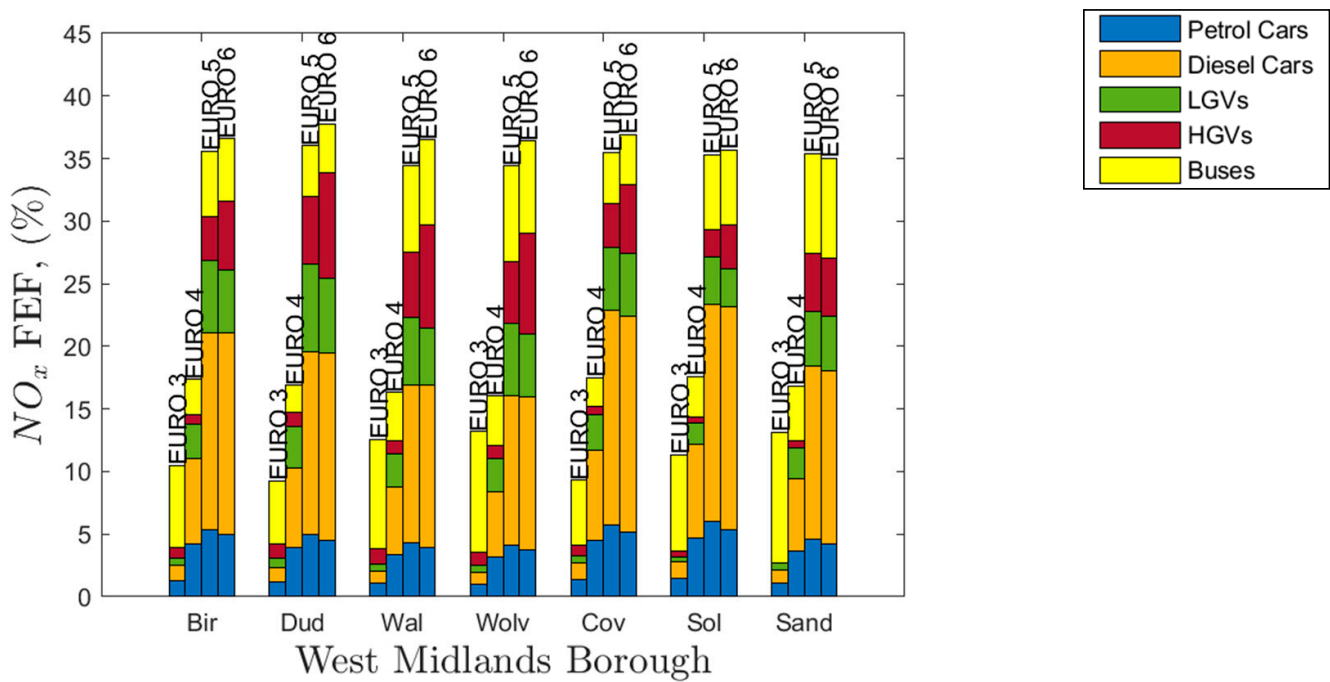

(a) $\mathrm{NO}_{x}$
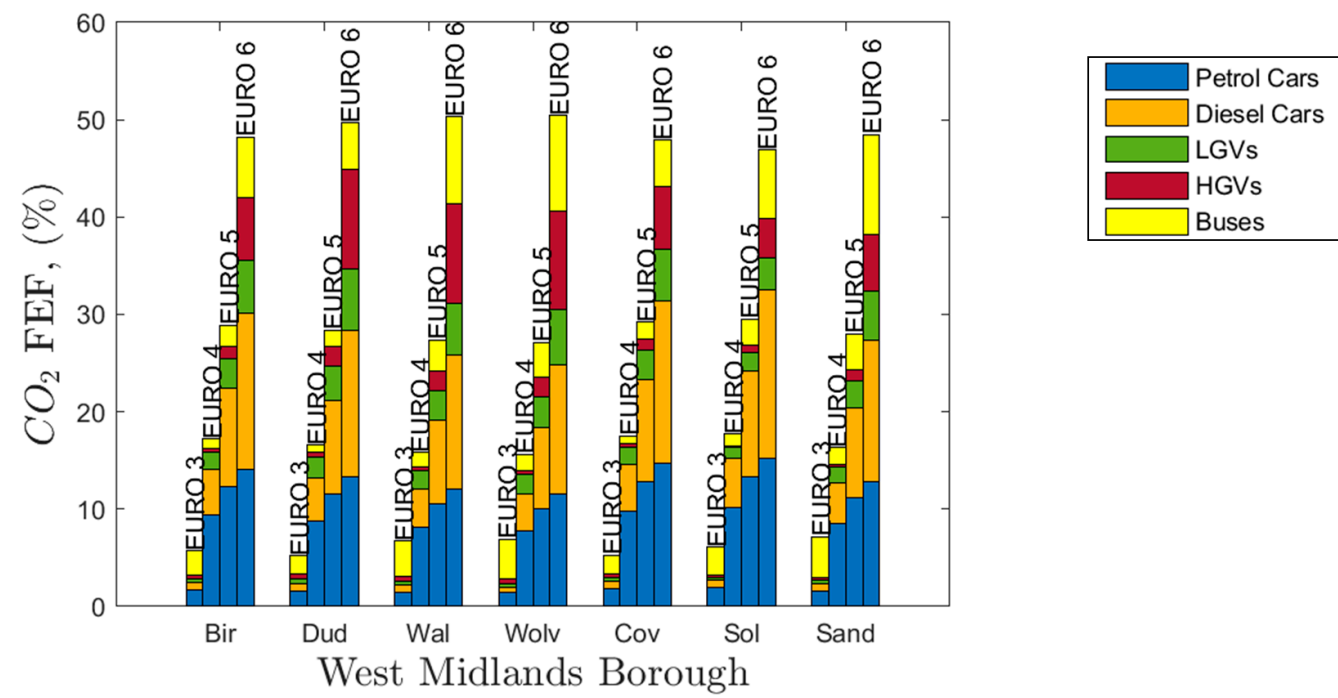

(b) $\mathrm{CO}_{2}$
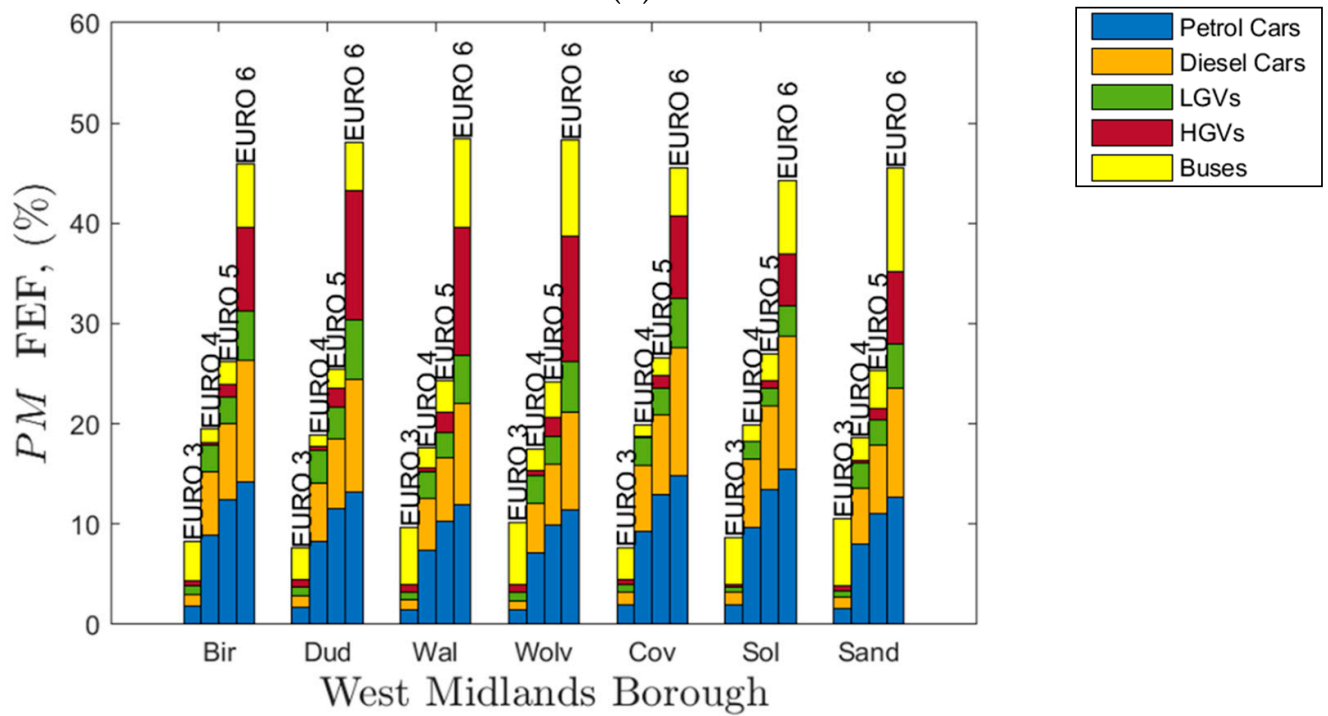

(c) PM

Figure 4. The effect of electrification on the percentage reduction of total fleet emissions of (a) $\mathrm{NO}_{\mathrm{x}},(\mathbf{b}) \mathrm{CO}_{2}$, and (c) PM subset by EURO class and vehicle type on urban roads, for each West Midland borough. On the y-axis, (\%) is based on the total fleet emission. 
The viability of the FEF strategy depends on developments of the EV market uptake. Mitigation and climate policies in the UK mention the integration of EVs into vehicle fleets but have been largely unsuccessful in that they have not led to significant increases in EV adoption. There are several complex factors that contribute to this [47]. Studies also emphasise that the lack of charging infrastructure heavily influences the success of such strategies [8]. Although the electrification of the LGV fleet has been conducting for the past few decades, the transition from heavy or even medium-duty vehicles is less certain. Electric HGVs should support higher accumulated weights and meet varied arrays of travel demands compared with the light-duty EVs. There is also considerable uncertainty in the distance traveled of electric HGVs compared with that of the electric LGVs. Moreover, the charging and refueling infrastructures are quite sparse within high income countries, e.g., the UK, and are not yet being developed in other parts of the world. Nevertheless, the electrification of HDVs is an emerging field of research and technology, see, for example, $[48,49]$.

\subsection{Fleet Replacement Scenario, FRV Factor}

The result of fleet replacement in urban areas is shown in Figure 5. As can be seen, the upgrading of bus EURO standards has a relatively small effect on reductions of the studied pollutants compared to FEF. This is because the EURO upgrading approach does not completely remove exhaust emissions, unlike the FEF approach. For $\mathrm{NO}_{\mathbf{x}}$ (Figure 5a) and $\mathrm{CO}_{2}$ (Figure 5b) emissions, the replacement of all EURO 5 vehicle types with EURO 6 would have the greatest reduction potential among the other cases, this is a large value because EURO 5 vehicles make the majority of the fleet that are not already EURO 6. For PM (Figure 5c), the replacement of the EURO 4 fleet has the highest reduction potential. Figure 5a shows EURO 5 upgrading would yield $\mathrm{NO}_{\mathrm{x}}$ reductions ranging from $10.0 \%$ to $10.4 \%$ with less variation, but lower efficacy, between boroughs compared to $\mathrm{NO}_{\mathrm{x}} \mathrm{FEF}$. The highest $\mathrm{NO}_{x}$ FRV is for EURO 5 diesel cars, where reductions range from $4.6 \%$ to $5.1 \%$. The replacement of HGVs has lower emissions reductions across all studied pollutants compared to FEF.

In Figure 5b, EURO 5 vehicles have the highest $\mathrm{CO}_{2}$ FRV ranging from $6.0 \%$ to $6.4 \%$ which is a considerably lower range than the $\mathrm{CO}_{2}$ FEF. The replacement of EURO 5 diesel cars makes up $>5 \%$ of total fleet $\mathrm{CO}_{2}$ reductions in all seven boroughs. Upgrading of EURO 5 petrol cars does not affect $\mathrm{CO}_{2}$ emissions [19]; hence, the $\mathrm{CO}_{2}$ FRV for this vehicle type was not quantified. The replacement of EURO $5 \mathrm{HGVs}$ would increase $\mathrm{CO}_{2}$ and PM emissions (shown as by negative FRV) in WM boroughs. Figure 5c shows the replacement of EURO 4 vehicles has the highest PM reductions across all boroughs ranging from $4.0 \%$ to $4.2 \%$. Again, the majority of reductions would come from replacing diesel vehicles. The PM FRV of EURO $4 \mathrm{LGVs}$ ranges from $0.5 \%$ to $1.0 \%$. There are also notable increases in PM emissions from the upgrading of EURO 4 and 5 HGVs, which would lead to additional PM emissions of up to $2.3 \%$. However, the real-world PM emission factors measured by VERSSs are usually less certain compared with the other measured EFs, see for example [44].

The real-world emission reductions through fleet replacement are minimal compared to reductions through fleet electrification, and in some cases, the replacement could increase pollutant emissions. Based on the results of this study the best course of action for the West Midlands would be to implement the fleet electrification scenario for all EURO 6 vehicles in urban areas to reduce the emissions of the studied pollutants. Fleet electrification would be especially beneficial for EURO 6 diesel cars and EURO 3 buses as these make up a considerable proportion of local $\mathrm{NO}_{\mathrm{x}}$ emissions. 

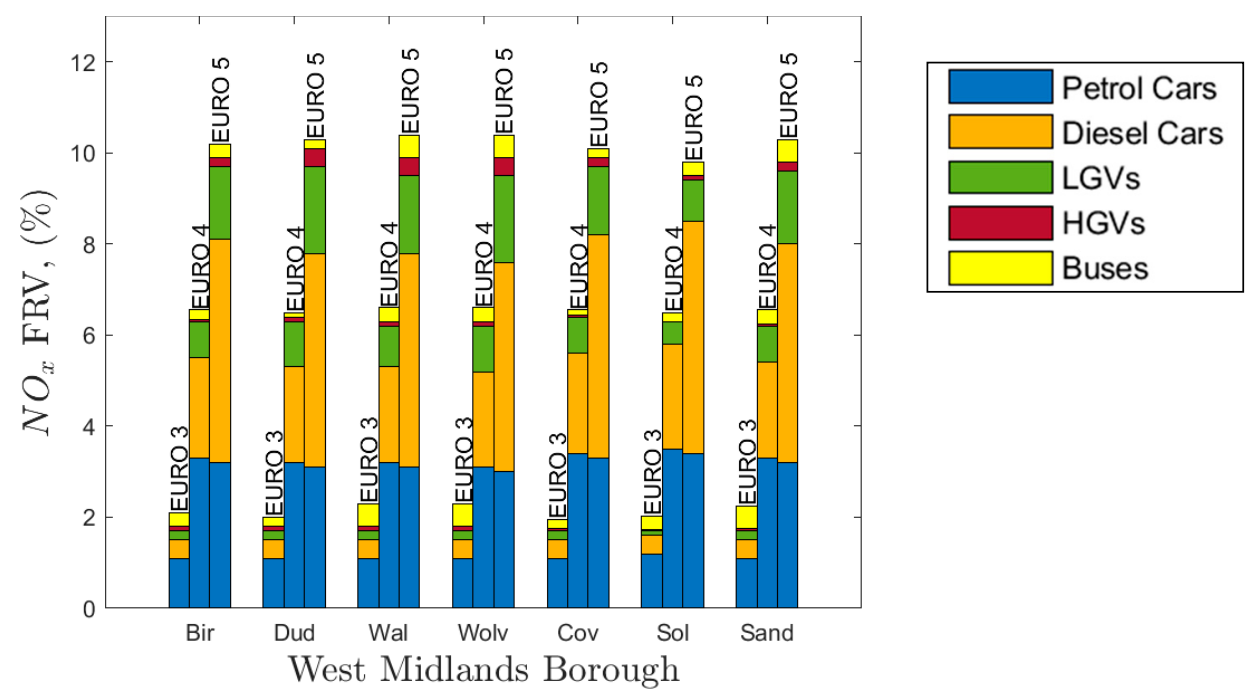

(a) $\mathrm{NO}_{x}$
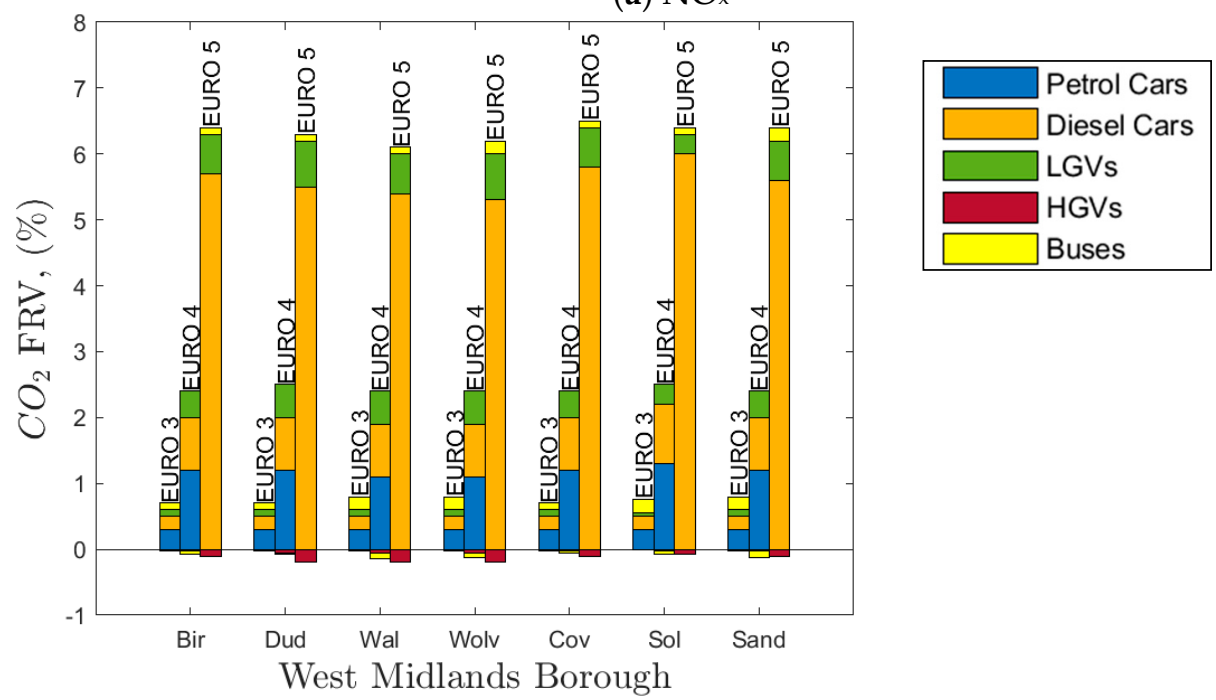

(b) $\mathrm{CO}_{2}$
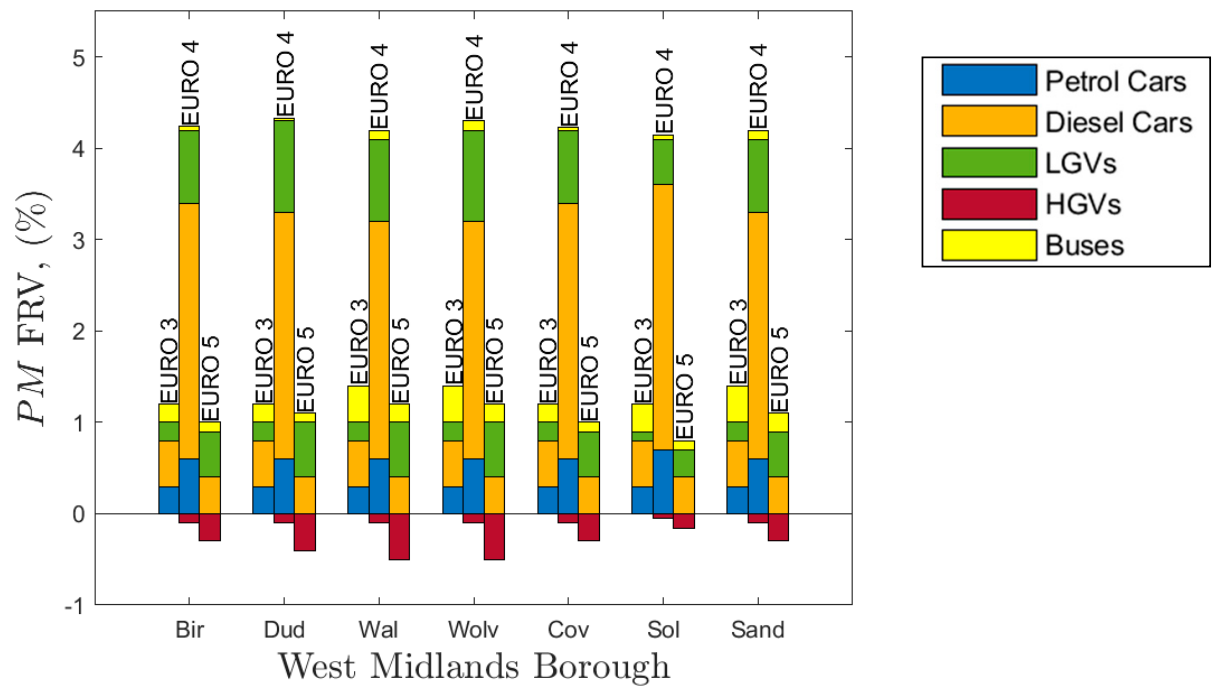

(c) PM

Figure 5. The effect of fleet replacement on the percentage reduction of total fleet emissions of (a) $\mathrm{NO}_{\mathrm{x}},(\mathbf{b}) \mathrm{CO}_{2}$, and (c) $\mathrm{PM}$ subset by EURO class and vehicle type on urban roads, for each West Midland borough. On the y-axis, $(\%)$ is based on the total fleet emission. 


\subsection{Mitigation Scenarios in the Other WM Road Types and Other Countries}

The efficacy of the FEF and FRV scenarios were also studied for rural roads and motorways in the WM. The reader is invited to see Supplementary Material for more information. Fleet electrification of EURO 6 vehicles has the highest reduction potential on both motorways and urban roads, across all pollutants and boroughs. Diesel vehicles also have a high reduction potential in these areas, especially for $\mathrm{NO}_{\mathrm{x}}$ and $\mathrm{CO}_{2}$ emissions. On motorways, HGVs represent the largest proportion of reductions through EV replacement. Electrification of these high emitters would be most promising for the management of PM emissions compared to the upgrading of HGVs which result in large increases in pollutant emissions in some cases. The reduction of air pollution concentrations in city centres with low populations provides little health benefits [50]. In the same way, the motorway emissions of $\mathrm{NO}_{x}$ and $\mathrm{PM}$ have lower significance in terms of human health as motorways are typically not situated in populous areas. The influence of fleet scenarios on this road type is best considered for contributions to climate change through $\mathrm{CO}_{2}$ emissions.

Table 5 summarises the efficacy of the studied FEF and FRV scenarios in the reduction of on-road emissions in different roads of West Midlands boroughs and other world regions. The FEF and FRV factors for motorway and rural roads were presented in detail in the Supplementary Material. The reduction potentials of the studied pollutants are greater on motorways than on both rural and urban roads. This may be attributed to the fleet composition of vehicle classes on each road type. In particular, HGVs frequently travel within motorway networks, therefore the electrification of the vehicle fleet on motorway roads has an extremely high PM reduction potential and the greatest $\mathrm{CO}_{2}$ emission reduction among the fleet in the other WM road types. Unfortunately, the HGV vehicle class is the least promising for electrification because of the power requirements. When compared to the existing literature, the analysis in this paper on the West Midlands highlights a higher potential for emission reduction except for Beijing, as the study in [27] accounts for the progression to a cleaner energy mix.

Table 5. The FEF and FRV factors in different places.

\begin{tabular}{cccc}
\hline \multicolumn{4}{c}{ West Midlands (Urban Roads) } \\
\hline \multirow{2}{*}{ Scenario } & NO $_{\mathbf{x}}$ Emission & PM Emission & CO $_{2}$ Emission \\
& Reduction (\%) & Reduction (\%) & Reduction (\%) \\
\hline FEF & $35.0-37.9$ & $44.3-48.3$ & $46.9-50.3$ \\
FRV & $10.0-10.4$ & $4.0-4.2$ & $6.0-6.4$ \\
\hline FEF & $42.7-46.0$ & West Midlands (Motorways) \\
FRV & $10.8-11.1$ & $54.3-64.3$ & $54.4-62.3$ \\
\hline FEF & $3.9-4.7$ & $6.4-7.2$ \\
\hline FRV & $40.3-42.9$ & West Midlands (Rural Roads) \\
\hline FEF & $10.3-10.8$ & $47.9-55.8$ \\
FRV & \multicolumn{4}{c}{$4.2-4.4$} \\
\hline
\end{tabular}




\section{Conclusions}

In this study, two mitigation scenarios were assessed for their real-world efficacy in reducing on-road emissions of $\mathrm{NO}_{x}, \mathrm{PM}$, and $\mathrm{CO}_{2}$ in West Midland boroughs. On urban roads, fleet electrification would result in maximum reductions of $35.0-37.9 \%, 44.3-48.3 \%$, $46.9-50.3 \%$ for $\mathrm{NO}_{x}, \mathrm{PM}$, and $\mathrm{CO}_{2}$, respectively. Due to their vehicle fleet characteristics, the boroughs of Wolverhampton, Walsall, Dudley, and Sandwell would benefit the most from this approach. In comparison, adoption of fleet renovation would lead to reductions ranging from $10.0-10.4 \%, 4.0-4.2 \%$, and $6.0-6.4 \%$ for $\mathrm{NO}_{\mathrm{x}}, \mathrm{PM}$, and $\mathrm{CO}_{2}$ respectively, with little variation between boroughs. Fleet replacement is not recommended due to its low real-world efficacy. Additionally, the upgrading of HGVs would lead to considerable increases in the emission of $\mathrm{PM}$ and $\mathrm{CO}_{2}$ in some cases. The results of this study may provide direction for local approaches as the implementation of fleet electrification and could have significant implications for future air quality in the West Midlands. According to the significant contribution of renewable energies to the UK energy trend, electrification might be considered as a promising solution to tackle exhaustive emissions, air pollution, and climate change.

In view of the research conducted in this paper, we make two distinct recommendations for future research:

- Explore how these emissions reductions would affect population exposure to the studied pollutants and possibly quantifying local health and economic benefits. This would allow the economic consequences of fleet change to be balanced with health and wider economic benefits.

- To take this further repeat investigation in other regions of the UK and quantify how $\mathrm{CO}_{2}$ emission reductions through these strategies would meet air quality guidelines and contribute to the UK's 2030 targets set out in the Climate Change Act 2008.

Supplementary Materials: The following are available online at https:/ /www.mdpi.com/2073-4 433/12/3/332/s1, Figure S1: The effect of fleet electrification on motorway emissions of (a) NOx, (b) $\mathrm{CO}$, and (c) PM in West Midlands boroughs. On the y-axis, (\%) is based on the total fleet emission; Figure S2: The effect of fleet renovation on motorway emissions of (a) $\mathrm{NOx}$, (b) $\mathrm{CO}_{2}$, and (c) PM in West Midlands boroughs. On the y-axis, (\%) is based on the total fleet emission; Figure S3: The effect of fleet electrification on rural road emissions of (a) NOx, (b) $\mathrm{CO}_{2}$, and (c) PM in West Midlands boroughs. On the y-axis, (\%) is based on the total fleet emission; Figure S4: The effect of fleet renovation on rural road emissions of (a) $\mathrm{NOx}$, (b) $\mathrm{CO}_{2}$, and (c) PM in West Midlands boroughs. On the y-axis, (\%) is based on the total fleet emission.

Author Contributions: Conceptualization, O.G. and F.D.P.; methodology, O.G. and F.D.P.; Software, O.G. and L.K.O.; investigation, O.G., F.D.P., and L.K.O.; writing-review and editing, O.G., F.D.P., and L.K.O.; visualization, O.G. and L.K.O.; supervision, F.D.P. All authors have read and agreed to the published version of the manuscript

Funding: The research was funded by the Department for Transport, UK (DfT), Transport Scotland, Transport Systems Catapult, UK (TSC), and Natural Environment Research Council, NERC (NE/S003487/1).

Data Availability Statement: Data for Figures 4 and 5 are available at https://doi.org/10.25500 /edata.bham.00000618.

Conflicts of Interest: The authors declare no conflict of interest.

\section{References}

1. Wang, J.; Feng, L.; Tang, X.; Bentley, Y.; Höök, M. The implications of fossil fuel supply constraints on climate change projections: A supply-side analysis. Futures 2017, 86, 58-72. [CrossRef]

2. Bartholy, J.; Pongrácz, R. A brief review of health-related issues occurring in urban areas related to global warming of $1.5^{\circ} \mathrm{C}$. Curr. Opin. Environ. Sustain. 2018, 30, 123-132. [CrossRef]

3. Singh, A.B.; Mathur, C. Climate Change and Pollen Allergy in India and South Asia. Immunol. Allergy Clin. N. Am. 2021, 41, 33-52. [CrossRef] 
4. Williams, M.L. Global warming, heat-related illnesses, and the dermatologist. Int. J. Women's Dermatol. 2020, 7, 70-84. [CrossRef]

5. Feng, C.; Sun, L.-X.; Xia, Y.-S. Clarifying the "gains" and "losses" of transport climate mitigation in China from technology and efficiency perspectives. J. Clean. Prod. 2020, 263, 121545.

6. Guan, W.-J.; Zheng, X.-Y.; Chung, K.F.; Zhong, N.-S. Impact of air pollution on the burden of chronic respiratory diseases in China: Time for urgent action. Lancet 2016, 388, 1939-1951. [CrossRef]

7. Höök, M.; Tang, X. Depletion of fossil fuels and anthropogenic climate change-A review. Energy Policy 2013, 52, 797-809. [CrossRef]

8. Nanaki, E.A.; Koroneos, C.J. Climate change mitigation and deployment of electric vehicles in urban areas. Renew. Energy 2016, 99, 1153-1160. [CrossRef]

9. Hill, G.; Heidrich, O.; Creutzig, F.; Blythe, P. The role of electric vehicles in near-term mitigation pathways and achieving the UK's carbon budget. Appl. Energy 2019, 251, 113111. [CrossRef]

10. Ghaffarpasand, O.; Khodadadi, M.; Majidi, S.; Rozatian, A.S.H. Multi-Elemental Characterization of PM0.4-0.7 and PM1.1-2.1 in the Ambient Air of Isfahan (Iran) Complemented by the Speciation of Mn and Cr Using SR-XANES. Aerosol Sci. Eng. 2020, 4, 124-136. [CrossRef]

11. Wei, Y.; Wang, Y.; Di, Q.; Choirat, C.; Wang, Y.; Koutrakis, P.; Zanobetti, A.; Dominici, F.; Gamble, C.J.; Schwartz, J.D. Short term exposure to fine particulate matter and hospital admission risks and costs in the Medicare pop-ulation: Time stratified, case crossover study. BMJ Br. Med. J. (Online) 2019, 367. [CrossRef]

12. Ali, Y.; Socci, C.; Pretaroli, R.; Severini, F. Economic and environmental impact of transport sector on Europe economy. Asia-Pacific J. Reg. Sci. 2017, 2, 361-397. [CrossRef]

13. Limani, Y. Applied Relationship between Transport and Economy. IFAC-PapersOnLine 2016, 49, 123-128. [CrossRef]

14. European Commission. EU Transport Figures—Statistical Pocket Book; European Commission: Brussels, Belgium, 2018 ; pp. 19-21.

15. Hofmann, J.; Guan, D.; Chalvatzis, K.; Huo, H. Assessment of electrical vehicles as a successful driver for reducing CO2 emissions in China. Appl. Energy 2016, 184, 995-1003. [CrossRef]

16. Gryparis, E.; Papadopoulos, P.; Leligou, H.C.; Psomopoulos, C.S. Electricity demand and carbon emission in power generation under high penetration of electric vehicles. A European Union perspective. Energy Rep. 2020, 6, 475-486. [CrossRef]

17. Xue, M.; Lin, B.-L.; Tsunemi, K. Emission implications of electric vehicles in Japan considering energy structure tran-sition and penetration uncertainty. J. Clean. Prod. 2021, 280, 124402.

18. Ke, W.; Zhang, S.; Wu, Y.; Zhao, B.; Wang, S.; Hao, J. Assessing the Future Vehicle Fleet Electrification: The Impacts on Regional and Urban Air Quality. Environ. Sci. Technol. 2016, 51, 1007-1016. [CrossRef]

19. Ghaffarpasand, O.; Talaie, M.R.; Ahmadikia, H.; TalaieKhozani, A.; Davari Shalamzari, M.; Majidi, S. Real-world assessment of urban bus transport in a medium-sized city of the Middle East: Driving behavior, emission performance, and fuel consumption. Atmos. Poll. Res. 2021, 12, 113-124. [CrossRef]

20. Ghaffarpasand, O.; Talaie, M.R.; Ahmadikia, H.; TalaieKhozani, A.; Davari Shalamzari, M.; Majidi, S. On-road performance and emission characteristics of CNG-gasoline bi-fuel taxis/private cars at the roadside environment. Atmos. Poll. Res. 2020, 11, 1743-1753. [CrossRef]

21. Kang, Y.; Li, Z.; Lv, W.; Xu, Z.; Zheng, W.X.; Chang, J. High-emitting vehicle identification by on-road emission remote sensing with scarce positive labels. Atmos. Environ. 2021, 244, 117877. [CrossRef]

22. Mudway, I.S.; Dundas, I.; Wood, H.E.; Marlin, N.; Jamaludin, J.B.; Bremner, S.A.; Cross, L.; Grieve, A.; Nanzer, A.; Barrattet, B.M.; et al. Impact of London's low emission zone on air quality and children's respiratory health: A sequential annual cross-sectional study. Lancet Public Health 2019, 4, e28-e40.

23. Mayor, L. ULEZ reduces 13,500 cars daily \& cuts toxic air pollution by a third. Off. Lond. Mayor 2019. [CrossRef]

24. Hao, H.; Wang, H.; Ouyang, M. Fuel conservation and GHG (Greenhouse gas) emissions mitigation scenarios for China's passenger vehicle fleet. Energy 2011, 36, 6520-6528. [CrossRef]

25. Guo, X.; Fu, L.; Ji, M.; Lang, J.; Chen, D.; Cheng, S. Scenario analysis to vehicular emission reduction in Beijing-Tianjin-Hebei (BTH) region, China. Environ. Pollut. 2016, 216, 470-479. [CrossRef]

26. Gerstenberger, M.; Listl, G. Impact analysis of changes in passenger vehicle fleet composition to reduce the NO2 im-missions. Transp. Res. Procedia 2019, 41, 708-721.

27. Wang, L.; Yu, Y.; Huang, K.; Zhang, Z.; Li, X. The inharmonious mechanism of CO2, NOx, SO2, and PM2.5 electric vehicle emission reductions in Northern China. J. Environ. Manag. 2020, 274, 111236. [CrossRef]

28. Ropkins, K.; DeFries, T.H.; Pope, F.; Green, D.C.; Kemper, J.; Kishan, S.; Fuller, G.W.; Li, H.; Sidebottom, J.; Crilley, L.R.; et al. Evaluation of EDAR vehicle emissions remote sensing technology. Sci. Total Environ. 2017, 609, 1464-1474. [CrossRef]

29. Foxon, T.J. Transition pathways for a UK low carbon electricity future. Energy Policy 2013, 52, 10-24. [CrossRef]

30. Barnes, J.; Hayes, E.; Chatterton, T.; Longhurst, J. Policy disconnect: A critical review of UK air quality policy in relation to EU and LAQM responsibilities over the last 20 years. Environ. Sci. Policy 2018, 85, 28-39. [CrossRef]

31. Department for Environmental Food and Rural Affairs. Air Pollution in UK 2019; Defra: London, UK, 2020. Available online: https:/ / uk-air.defra.gov.uk/library/annualreport/viewonline?year=2019_issue_1 (accessed on 14 February 2021).

32. Shehab, M.A.; Pope, F.D. Effects of short-term exposure to particulate matter air pollution on cognitive performance. Sci. Rep. 2019, 9, 1-10. [CrossRef] 
33. Trading Economics. United Kingdam GDP from Transport. 2020. Available online: https://tradingeconomics.com/unitedkingdom/gdp-from-transport (accessed on 1 November 2020).

34. Holgate, S.T. Every breath we take: The lifelong impact of air pollution-A call for action. Clin. Med. 2017, 17, 8-12.

35. European Environment Agency. Air Quality in Europe-2020 Report; Publication office of European Union: Luxembourg, 2020; Available online: https://www.eea.europa.eu/publications/air-quality-in-europe-2020-report/at_download/file (accessed on 14 February 2021).

36. Ellison, R.B.; Greaves, S.P.; Hensher, D.A. Five years of London's low emission zone: Effects on vehicle fleet composi-tion and air quality. Transp. Res. Part D Transp. Environ. 2013, 23, 25-33.

37. BCC. Birmingham Clean Air Zone Feasibility Study; Birmingham City Council: Birmingham, UK, 2018; Available online: https://www.birminghambeheard.org.uk/economy/caz_organisation/supporting_documents/Air\%20Quality\%20 Modelling\%20Report.pdf (accessed on 14 February 2021).

38. Department for Business, Energy, and Industrial Strategy. Energy Trend. June 2020. Available online: https://assets.publishing. service.gov.uk/government/uploads/system/uploads/attachment_data/file/923057/Energy_Trends_June_2020.pdf (accessed on 14 February 2021).

39. BCC. Black Country Consortium: Black Country Economy. 2019. Available online: https://www.the-blackcountry.com/ economic-intelligence-unit/black-country-economy (accessed on 21 December 2020).

40. West Midlands Combined Authority. State of the Region 2020: Executive Summary; West Midland Combined Authority, Office for National Statistics: Birmingham, UK. Available online: https://governance.wmca.org.uk/documents/s4470/Economic\%20 Recovery\%20Appendix\%201.pdf (accessed on 14 February 2021).

41. Office for National Statistics. Population Estimates. Available online: https:/ / www.ons.gov.uk/peoplepopulationandcommunity/ populationandmigration/populationestimates (accessed on 14 February 2021).

42. Office for National Statistics. Annual GDP for England, Wales and the English Regions: Time-Series. 2019. Available online: https:/ / www.ons.gov.uk/ filter-outputs/07a2a97a-7899-40d9-800e-b01965106476 (accessed on 14 February 2021).

43. National Atmospheric Emission Inventory. Fleet Composition of Outside London. Available online: https://naei.beis.gov.uk (accessed on 14 February 2021).

44. Ghaffarpasand, O.; Beddows, D.C.; Ropkins, K.; Pope, F.D. Real-world assessment of vehicle air pollutant emissions subset by vehicle type, fuel and EURO class: New findings from the recent UK EDAR field campaigns, and implications for emissions restricted zones. Sci. Total Environ. 2020, 734, 139416. [CrossRef]

45. Grigoratos, T.; Martini, G. Brake wear particle emission: A review. Environ. Sci. Poll. Res. 2015, 22, 2491-2504. [CrossRef]

46. Beddows, D.C.; Harrison, R.M. PM10 and PM2.5 emission factors for non-exhaust particles from road vehicles: Dependence upon vehicle mass and implications for battery electric vehicles. Atmos. Environ. 2021, 244, 117886. [CrossRef]

47. Heidrich, O.; Hill, G.A.; Neaimeh, M.; Huebner, Y.; Blythe, P.T.; Dawson, R.J. How do cities support electric vehicles and what difference does it make? Technol. Forecast. Soc. Chang. 2017, 123, 17-23. [CrossRef]

48. Forrest, K.; Mac Kinnon, M.; Tarroja, B.; Samuelsen, S. Estimating the technical feasibility of fuel cell and battery electric vehicles for the medium and heavy duty sectors in California. Appl. Energy 2020, 276, 115439. [CrossRef]

49. Lee, D.-Y.; Elgowainy, A.; Kotz, A.; Vijayagopal, R.; Marcinkoski, J. Life-cycle implications of hydrogen fuel cell electric vehicle technology for medium- and heavy-duty trucks. J. Power Sources 2018, 393, 217-229. [CrossRef]

50. Lee, D.; Robertson, C.; Ramsay, C.; Gillespie, C.; Napiera, G. Estimating the health impact of air pollution in Scotland, and the resulting benefits of reducing concentra-tions in city centres. Spat. Spatio-Temporal Epidemiol. 2019, 29, 85-96. 